\title{
Live dynamic imaging of caveolae pumping targeted antibody rapidly and specifically across endothelium in the lung
}

\author{
Phil Oh ${ }^{1}$, Per Borgström ${ }^{1}$, Halina Witkiewicz ${ }^{1}$, Yan $\mathrm{Li}^{1}$, Bengt J Borgström ${ }^{2}$, Adrian \\ Chrastina ${ }^{1}$, Koji Iwata ${ }^{3}$, Kurt R Zinn ${ }^{4}$, Richard Baldwin ${ }^{1}$, Jacqueline E Testa ${ }^{1}$, and Jan E \\ Schnitzer ${ }^{1}$ \\ 1 Sidney Kimmel Cancer Center, 10905 Road to the Cure, San Diego, California 92121, USA \\ 2 EE Department, University of California, Los Angeles, Box 951594, Los Angeles, California 90095, USA \\ 3 Gamma Medica, Inc., 19355 Business Center Drive, Suite \#18, Northridge, California 91324, USA \\ 4 Departments of Medicine, Radiology \& Pathology, University of Alabama at Birmingham, 1808 Seventh \\ Avenue South, Birmingham, Alabama 35294, USA
}

\begin{abstract}
How effectively and quickly endothelial caveolae can transcytose in vivo is unknown, yet critical for understanding their function and potential clinical utility. Here we use quantitative proteomics to identify aminopeptidase $\mathrm{P}$ (APP) concentrated in caveolae of lung endothelium. Electron microscopy confirms this and shows that APP antibody targets nanoparticles to caveolae. Dynamic intravital fluorescence microscopy reveals that targeted caveolae operate effectively as pumps, moving antibody within seconds from blood across endothelium into lung tissue, even against a concentration gradient. This active transcytosis requires normal caveolin-1 expression. Whole body $\gamma$-scintigraphic imaging shows rapid, specific delivery into lung well beyond that achieved by standard vascular targeting. This caveolar trafficking in vivo may underscore a key physiological mechanism for selective transvascular exchange and may provide an enhanced delivery system for imaging agents, drugs, gene-therapy vectors and nanomedicines. 'In vivo proteomic imaging' as described here integrates organellar proteomics with multiple imaging techniques to identify an accessible target space that includes the transvascular pumping space of the caveola.
\end{abstract}

Caveolae are caveolin-coated, omega-shaped plasmalemmal invaginations $60-70 \mathrm{~nm}$ in diameter that bud from the plasma membrane in a dynamin and GTP-dependent manner 1,2 . They are especially abundant in vascular endothelia, where they function in endocytosis and transcytosis to traffic select macromolecules and to maintain tissue homeostasis. Caveolin knockout mice exhibit poor endothelial cell barrier function with compensatory tissue disruption and edema, particularly evident in the lung 3,4 . The study of trafficking by caveolae

Correspondence should be addressed to J.E.S. (jschnitzer@skcc.org).

Note: Supplementary information is available on the Nature Biotechnology website.

AUTHOR CONTRIBUTIONS

P.O., Figures 1a,c, 2, 3, 4, 6, Supplementary Figures 2b,c, 3b-d, 4, 5, subcellular fractionation, immunoblotting, lentiviral gene silencing siRNA, animal surgical procedures, intravital microscopy imaging and analysis, fluorophore and ${ }^{125} \mathrm{I}$ labeling of proteins, A-SPECT and X-SPECT imaging, Supplementary Videos 1-6; P.B., Figures 2, 3, 4, 5, intravital microscopy and analysis, Supplementary Videos 1, 2; H.W., Figure 1b, c, all electron microscopy imaging and analysis; Y.L., Supplementary Figures 1 and 2a, mass spectrometry (MS) and analysis of MS data; B.J.B., Figures 4, 5, intravital microscopy image processing, custom MatLab scripting; A.C., Figure 7a-c, XSPECT imaging, radiolabeling, Supplementary Figure 5; K.I., Figure 6a, bj, k, m, Supplementary Videos 3-6; K.R.Z., Figure 7d-f; R.B., Figure 1c, gold particle preparation; J.E.T., Figure 1a, Supplementary Figures 3a, b and 5, monoclonal antibody production, screening and characterization; J.E.S., manuscript, experiment design and result analysis.

COMPETING INTERESTS STATEMENT

The authors declare that they have no competing financial interests. 
has been hampered by a lack of caveolae-specific probes. This is especially true for the caveolae of endothelial cells, which in cell culture exhibit phenotypic drift, including altered protein expression $^{5,6}$ and a greater than tenfold decrease in caveolae density ${ }^{7}$. Studies of caveolae trafficking in many types of cultured cells have suggested that caveolae mediate endocytosis at a much slower rate than that observed for clathrin-mediated trafficking $(1-2 \mathrm{~h}$ versus $5-10$ $\min )^{8-10}$. Caveolae have even been described as static structures that do not constitutively traffic cargo $11-13$. In vivo data on caveolae trafficking are conspicuously lacking. Electron microscopy (EM) has provided static images supporting transendothelial transport ${ }^{14-16}$, but usually in situ with probes that are not specific for caveolae ${ }^{17,18}$.

One of the major challenges in delivering imaging agents, drugs, nanoparticles or gene therapies to specific tissues of the body is overcoming endothelial and epithelial cell barriers that prevent entry into tissue compartments $17,19-24$. For example, the treatment of multiple genetic and acquired diseases of the lung, such as cystic fibrosis, lung cancer, pulmonary fibrosis, pulmonary hypertension and acute respiratory distress syndrome, could benefit from a means of delivering agents across the endothelial barrier to the cells deeper in the tissue ${ }^{19}$, 25-27. Vascular targeting is directed towards the accessible endothelial cell surface of blood vessels feeding the tissue rather than relatively inaccessible sites located on cells inside the tissue $10,17,18,24,28-31$. Agents injected into the blood have direct and almost immediate exposure to the vascular endothelial cell surface, including its caveolae $14,17,32$. Whether proteins with sufficient tissue specificity exist at this critical blood-tissue interface is unclear $^{33}$, however, and rapid tissue-specific targeting with high blood extraction has seldom been attained and validated in vivo 14,24,34-36.

It has been hypothesized $17,18,29,32$ that targeting caveolae may improve specific delivery into select tissues beyond standard vascular targeting by providing a transcellular trafficking pathway that overcomes normal barriers. Here we use an in vivo proteomic mapping and imaging strategy to discover and validate targets in lung endothelial caveolae as useful for achieving tissue-specific targeting. We develop and characterize antibody probes to lung endothelial cell-surface proteins and use small-animal imaging techniques to provide a dynamic, sensitive and quantitative visualization of tissue-specific vascular targeting and transendothelial transport in vivo.

\section{RESULTS}

\section{Mapping aminopeptidase $\mathbf{P}$ to lung endothelial caveolae}

To identify proteins highly concentrated in caveolae of vascular endothelium, we isolated luminal endothelial cell-surface caveolae directly from rat lungs using a colloidal silica nanoparticle-coating technique 37,38 . Using mass spectrometry and database searching to identify peptide sequences and assess cumulative mass spectral intensities for each protein, we identified aminopeptidase P (APP) as having the highest cumulative spectral signal in the caveolae, even exceeding that of the caveolae structural protein, caveolin, by greater than tenfold (see Supplementary Data online). Supplementary Figure 1 online shows several tandem mass spectrometry (MS/MS) spectra and the $>50 \%$ sequence coverage for both proteins. Supplementary Table 1 online provides the peptides identified with charge status (49 and 17 unique tryptic peptides identified for APP and caveolin-1 $\alpha$, respectively). Similar to APP and caveolin, CD34 was also enriched more than tenfold in the isolated luminal endothelial cell plasma membranes over the lung homogenates. Yet, it was markedly depleted (tenfold or more) in the caveolae relative to these plasma membranes and had a mass spectrometric signal $0.3 \%$ of that for caveolin. As reported ${ }^{39},>97 \%$ of the isolated caveolae bound to magnetic beads conjugated to caveolin antibodies, consistent with abundant caveolin coating of caveolae and the reasonable purity of the preparation. 


\section{APP antibody specifically targets caveolae}

To create specific targeting probes, we generated and screened monoclonal antibodies to APP, CD34 and other endothelial cell-surface proteins, using the isolated rat lung luminal endothelial cell plasma membranes and purified recombinant proteins (Supplementary Data). Western blot analysis demonstrated antibody specificity (Fig. 1a) and confirmed the mass spectrometric quantification (described above) by showing both APP and caveolin $>20$-fold enriched in the isolated caveolae versus luminal endothelial plasma membranes. Although also enriched in the endothelial plasma membranes over the lung homogenate, CD34 was >20-fold depleted in the caveolae. Two monoclonal antibodies to APP recognized different epitopes, yet gave very similar results here and in the experiments below; hence, they were designated mAPP (see Supplementary Data and Supplementary Figs. 2 and 3). Lastly, EM showed that mAPP specifically immunolabels caveolae in vascular endothelium on ultra-thin cryosections of lung tissue (Fig. 1b) and can target colloidal gold nanoparticles to caveolae after pulmonary artery perfusion in situ (Fig. 1c). In both cases, labeling of caveolae by control antibodies was less than $2 \%$ of that by mAPP (data not shown).

\section{Dynamic imaging of antibody processing by endothelium in vivo}

To visualize in real time and in vivo the endothelial cell targeting and processing of the antibodies, including possible transport into the lung parenchyma, we performed intravital microscopy on live animals. Nude mice were fitted with a specialized dorsal skin window chamber containing grafted donor rat lung tissue, which revascularizes after 1-2 weeks. After tail vein injection of fluorophore-conjugated antibody, this tissue was monitored continuously by fluorescence microscopy and digital imaging. Figure 2 shows the rapid accumulation of mAPP in the lung but not nearby surrounding mouse tissue (also see Supplementary Video 1 and Supplementary Video 1 Legend online). Within $20 \mathrm{~s}$, green fluorescence was readily evident even at low magnification, and by 1 min was found throughout the lung tissue (Fig. 2b-e). Higher magnification (Fig. 2f) revealed fluorescent signal not only at the blood vessel walls but also apparently inside the tissue. The grafted tissue maintained rat blood vessels as indicated by the binding of mAPP, both of which recognize rat but not mouse APP. When we similarly tested grafted rat heart and liver tissues, we also detected fluorescent mAPP (30 $\mu \mathrm{g}$ injected) and blood cells circulating through the vessels but neither endothelial cell-surface binding nor interstitial accumulation. The specific uptake of mAPP was readily evident with much greater signal accumulation in lung (Fig. 2g).

When we focused at higher magnification on tissue regions very rich in microvessels, especially capillaries (Fig. 2h-o), the level of signal accumulation was indeed rapid and exceptionally strong. Within $5 \mathrm{~s}$ after intravenous injection, endothelial cell-surface binding was evident, and more easily discerned in microvessels $>10 \mu \mathrm{m}$ in radius. The signal increased most rapidly throughout the capillary-rich region (circled in Fig. 2h) compared with the blood or the perivascular space of larger vessels.

\section{Imaging APP antibody trafficking in solitary microvessels in vivo}

To gain more detailed information on antibody binding and transport, we performed experiments using solitary microvessels in regions without the complication of other vessels being nearby (within $200 \mu \mathrm{m}$, as assessed by focusing the light microscope through the tissue). We first injected $30 \mu \mathrm{g}$ of control monoclonal antibody to $\operatorname{IgG}(\mathrm{mIgG})$ and then $60 \mathrm{~s}$ later injected tenfold less $\mathrm{mAPP}$ (Fig. 3). The $\mathrm{mIgG}$ remained in the blood vessel with no detectable leakage over 10 min ( 1 and 4 min shown in Fig. 3b, j, respectively). Conversely, we detected very rapid binding of mAPP to the endothelial cell surface. It was evident as early as $4-5 \mathrm{~s}$ after injection (Fig. 3d) and increased in concentration to form a clear outline of the blood vessel wall over the next 5-10 s (Fig. 3e-g). Within $5 \mathrm{~s}$ of first detection of binding, fluorescence signal in the tissue outside the blood vessel was evident and progressively 
increased as the probe accumulated in the perivascular space. By $30 \mathrm{~s}$, the probe signal could be detected throughout the region of analysis as a gradient strongest near the vessel wall (Fig. $3 \mathrm{~h}$ ). The $\mathrm{mIgG}$ at ten times the dose of mAPP and over much longer post-injection times still remained in the vessel and in fact showed little overlapping signal with the mAPP (Fig. 3i). Experiments using caveolin antibody also showed neither targeting nor transport (data not shown), not surprising given the antibody's inaccessibility to the protein in the membrane (hairpin turn in lipid bilayer with $\mathrm{N}$ - and $\mathrm{C}$ termini inside cell).

Figures $3 \mathrm{k}-\mathrm{q}$ show that we also detected no interstitial accumulation of antibodies to endothelial cell-surface proteins that were not concentrated in caveolae. Although the monoclonal antibody to CD34 (mCD34) bound rapidly at the lung microvessel surface, it did not cross the endothelial cell barrier, even at 3.3 and 10 times the injected dose of mAPP (Fig. 31, o). Again, control mIgG remained in the vessel lumen (Fig. 3n, p) and did not bind and colocalize with CD34 antibody at the vessel wall (Fig. 3q). Extravasation of mCD34 as well as other probes ( $\mathrm{mIgG}$, large dextrans) was not detected even at $30 \mathrm{~min}$ after injection (data not shown). Thus, the observed transendothelial transport of mAPP is not due to nonspecific general leakiness of the vessels nor simply from general cell-surface binding. Rather it appears to be the specific immunotargeting of lung endothelial, APP-rich caveolae that greatly facilitates transport across the endothelial cell barrier to permit antibody penetration and concentration in the underlying tissue interstitium. This transport appears to require antibody binding specifically within caveolae.

\section{Caveolin knockdown prevents mAPP transport}

Caveolae are formed through the hetero-oligomerization of caveolins; repression of caveolin-1 expression, using specific interfering RNAs or genetic knockout of the caveolin-1 gene reduces or eliminates caveolae ${ }^{3,4}$. To lower the abundance of caveolae in the rat lung tissue implanted in the dorsal skin window chambers, we used lentivirally expressed short hairpin RNAs (shRNAs) against the caveolin-1 gene. The blood circulation appeared equivalent by intravital microscopy in tissue preparations receiving the lentiviral vector or control vector. After mAPP was injected intravenously, its binding to the endothelial cell surface was evident in both tissues. Rapid mAPP transendothelial transport was observed in the tissue infected with the control lentivirus but not in the tissue infected with the rat caveolin shRNA-expressing vector (Fig. 3r-w). With effective caveolin knockdown (see Supplementary Fig. 4a online), mAPP processing by the lung endothelium became similar to that seen with the non-caveolae-targeting mCD34 (compare Fig. 3t and o; both photographs show cell surface immunobinding but no transport). Consistent with these results, other experiments performed at low magnification showed a marked decrease in the overall lung tissue uptake with caveolin knockdown but not control (see Supplementary Fig. 4b). Thus, transendothelial transport of mAPP appeared to be caveolin and caveolae dependent.

\section{Image processing to quantify relative transvascular transport}

The probe signal emanated from the vessel wall into the tissue (see Supplementary Video 2 and Supplementary Video 2 Legend online) with the space nearest the vessel first becoming fluorescent and reaching the highest intensity (Fig. 3d-i). Subsequently the antibody signal was detected in deeper interstitial regions. To assess more fully this apparent progressive radial transport, we quantified the digital images on a frame-by-frame and pixel-by-pixel basis and created ensemble-averaged signal intensity profiles. Figure $4 \mathrm{a}-\mathrm{f}$ shows the fluorescence signal as a function of linear distance perpendicular to the vessel wall ( $y$-axis) over time after injection ( $x$-axis). mAPP showed rapid binding and then progressive entry into the tissue, yielding an antibody-gradient profile that changed with time until it became constant and maximal at $~ 30$ s. This was not seen with the other antibodies. The mIgG control stayed in the vessel, and 
mCD34 remained concentrated at the vessel wall. Even at 10 times the mAPP dose, which created strong intravessel signals, there was little to no tissue permeation with either antibody.

Because blood vessels are cylindrical structures, we also quantified the statistically averaged digital image into polar plots (Fig. $4 \mathrm{~g}-\mathrm{l}$ ). This analysis shows even more clearly the movement of mAPP but not other antibodies through the cylindrical vessel wall into the tissue. The mCD34 rapidly bound to and stayed at the vessel wall, effectively concentrating at this interface. The control $\mathrm{mIgG}$ remained circulating inside the microvessel. Only the signal profile for mAPP shows transport across the vascular wall and perivascular accumulation.

Figure 4a, e shows that mAPP was not only bound and concentrated at the vessel wall (like mCD34) but was also actively pumped into the tissue, even against the concentration gradient. Within seconds of injection, mAPP was being actively transported by caveolae across the endothelium to the lung tissue at levels far exceeding the blood concentration. This did not occur in lung tissue after caveolin-1 knockdown, despite cell-surface binding (compare Fig. $4 \mathrm{a}$, e with $\mathbf{f}$, and $\mathbf{g}, \mathbf{k}$ with $\mathbf{l}$ ). Without caveolae, mAPP processing by endothelium is similar to that of mCD34 (compare Fig. $4 \mathrm{f}$ with $\mathbf{d}$, and $\mathbf{i}$ with $\mathbf{l}$ ).

Although the signal near the central axis of the blood vessel was very small after injection of $3 \mu \mathrm{g}$ mAPP, there was considerable signal at the vessel wall (dashed white line in Fig. 4) and a few $\mu \mathrm{m}$ just inside the vessel wall. The microscope picks up fluorescent signal with decreasing efficiency beyond the focal plane. Thus, the cylindrical geometry of the vessel produces signal from vessel-wall binding that becomes additive and extends into the vessel. This 'curvature effect' was readily apparent for both mAPP and mCD34 (Figs. 3 and 4) and in fact is the green fluorescence signal that shows the most overlap (yellow signal) with the $\mathrm{mIgG}$ red fluorescence signal at $60 \mathrm{~s}$ after injection (Fig. 3i, q).

To further analyze and quantify the transport, we measured the total accumulated signal in the whole observation window versus without intravessel signal (vessel wall + perivascular space) versus perivascular tissue signal starting $5 \mu \mathrm{m}$ beyond the vessel wall. As above, we avoided transport from other vessels by quantifying the signal only in a limited region most proximal to the vessel $(\sim 20 \mu \mathrm{m})$ and by using only relatively solitary microvessels with conveniently straight and cylindrical geometry. It was readily apparent that the intravessel signal and signal from the endothelial cell surface contributed to the cumulative tissue signal. However, neither represents transvascular transport. Greater than $99 \%$ of the detected tissue signal for $\mathrm{mIgG}$ and mCD34 could be attributed to the presence of antibody in the vessel or on the vessel wall. (Fig. $5 \mathrm{a}, \mathrm{b})$. Conversely, for mAPP, $77 \%$ of the total signal came from the perivascular space, with the remainder being vessel wall signal (including the "curvature effect") and very little intravessel signal (Fig. 5c). The dominant mAPP tissue signal moved within a few seconds from the endothelial cell surface to the perivascular space (compare time gap between curves in Fig. 5c and flux curves in Fig. 5d, e). The maximum intensity in this observation window was attained within 20-30 s. Area under the curve analysis over the first minute confirmed these findings (Fig. 5f). The antibodies, although labeled to equivalent fluorophore intensities, accumulated differently, with mAPP showing $>100$-fold more signal in the lung parenchyma even at tenfold lower injected dose (159- and 611-fold more than mCD34 and $\mathrm{mIgG}$,

respectively). Lastly, this advantage for mAPP was lost with lentiviral silencing of caveolin-1 gene expression (Fig. $5 \mathrm{~g}, \mathrm{~h}$ ), which reduced transport into the tissue $5 \mu \mathrm{m}$ beyond the vessel by $98 \%$.

Because we detected $<10 \%$ decrease in circulating mAPP signal and because the concentration in the blood $(\sim 10 \mathrm{nM})$ exceeds the equilibrium binding constant for the antibody $(1 \mathrm{nM})$, one would not expect the transport to become probe limited and in fact would expect a constant flux across the vessel wall to be maintained. From Figure $5 \mathrm{~d}$ we calculated an effective flux 
from the slope of interstitial signal accumulation ( $5 \mu \mathrm{m}$ curve). Regression analysis of the ascending portion of the tissue intensity curve (in this experiment 7-20 s) shows an excellent linear fit $\left(R^{2}>99 \%\right)$ with a constant slope of 4.6 that reflects the effective flux. Beyond $30 \mathrm{~s}$, the curve provides a good linear fit but with a slope approaching $0(0.19 \mathrm{AU} / \mathrm{s})$, reflecting not a change in transvascular flux but rather limitations imposed by the small observational space and the realities of an open tissue system with continued transport into the tissue beyond the perimeter of the measurement window. This efflux is negligible at the start but increases to nearly equal the transendothelial influx of antibody.

Analysis of the instantaneous flux determined by the first derivative (slope) at each time point shows a maximum flux at the inflection point of the ascension curve and then decreases beyond $30 \mathrm{~s}$ to oscillate around 0 (Fig. 5e). Both the overall flux (Fig. 5d) and the peak instantaneous flux that occurred at $\sim 13 \mathrm{~s}$ (Fig. 5e) were modestly influenced by the cell-surface binding, including the curvature effect. Without correction for binding and curvature effects, they would appear up to $20 \%$ greater. This analysis also shows that the true flux lagged only a few seconds behind the cell surface-binding signal. Once transcytosed, the antibody can move quickly, primarily driven convectively by normal water flow through the tissue. This antibody flux is largely lost without normal caveolin expression (Fig. $5 \mathrm{~g}$ ). With very fast transcytotic pumping of mAPP, the different accumulation and flux curves would exhibit a short lag period and would not effectively separate. If pumping were slow or ineffective, the signal at the cell surface would become more distinct from the other curves and contribute more to the overall signal (as seen for CD34 antibody and for mAPP after caveolin knockdown).

\section{Whole body imaging of lung targeting in vivo}

To assess the specificity and rapidity of lung targeting of mAPP in live animals using an alternative technique with whole native intact lungs, we performed dynamic planar gammascintigraphy on rats after tail vein injection of mAPP versus $\mathrm{mIgG}$. We captured $0.5 \mathrm{~s}$ images at $1 \mathrm{~s}$ intervals for $1 \mathrm{~min}$ after injection (Fig. 6a; Supplementary Video 3 and Supplementary Video 3 Legend online). During this dynamic live imaging, the two antibodies appeared virtually identical over the first $3-5 \mathrm{~s}$. By $10 \mathrm{~s}$, the lung silhouette was already discernable from the significant extraction of mAPP specifically in the lung. Even by $10 \mathrm{~s}$, a negative image of the heart cavity was apparent (see arrowhead in Fig. 6a). In contrast, control ${ }^{125} \mathrm{I}-\mathrm{mIgG}$ (Fig. $6 b$ ) was detected much more readily throughout the animal and exhibited little to no specific organ imaging or clearing of radioactivity from the blood-engorged heart and liver. Thus, this whole body imaging independently confirmed the intravital fluorescence microscopy studies. Both approaches detected very rapid and specific lung tissue uptake of caveolae-targeted mAPP within the first minute after injection.

To investigate whether caveolae targeting enhances tissue-specific delivery compared with vascular targeting, we intravenously injected several monoclonal antibodies specific for proteins expressed on the lung endothelial cell surface but not in caveolae (all antibodies ${ }^{125} \mathrm{I}$-labeled to $10 \mu \mathrm{Ci} / \mu \mathrm{g}$; see Supplementary Data and Supplementary Fig. 3 online for antibody characterization and expression profiling). These antibodies showed lung delivery of radio-nuclide with varying specificity and rapidity (Fig. $6 \mathrm{c}-\mathrm{m}$ ). mAPP produced the highestintensity lung image, which remained strong after $16 \mathrm{~h}$ (Fig. 6c) and even after $48 \mathrm{~h}$ (Fig. 6m). The liver sometimes showed a spotty signal that cleared quickly. This was probably due to the large blood volume in the liver and/or possible Fc-receptor binding 40 .

Consistent with the tissue immunostaining pattern (Supplementary Fig. 3), mCD34 also specifically targeted the lung to produce a clear lung image within 10 min that reached peak intensity at $1 \mathrm{~h}$ ( fourfold less than mAPP) but then quickly dissipated (Fig. 6d). Again, minor liver signal was detected at early time points and was weaker than that of control IgG (Fig. 6h). Unlike mAPP and mCD34, which showed no heart targeting (see arrow Fig. 6c, d), the 
ACE antibody signal was distributed throughout the thoracic cavity, consistent with ACE expression in both lung and heart luminal endothelial cell membranes (Supplementary Fig. 3). This signal intensity reached a maximum intensity at $1 \mathrm{~h}$ before diminishing significantly by $16 \mathrm{~h}$ (Fig. 6e). Lung uptake of podocalyxin and PECAM antibody was substantial but less (7fold and 20-fold, respectively) than that observed for mAPP. These two antibodies also targeted other organs, including kidney (Fig. 6f) and liver (Fig. 6g). Previous study of PECAM antibody biodistribution also revealed accumulation in lung and liver ${ }^{35}$. Control nontargeting IgGs distributed diffusely throughout the animal, especially in high-blood volume regions of the chest (heart and lung) and abdomen (liver and spleen) (Fig. 6h). Lastly, the lung targeting of ${ }^{125} \mathrm{I}$-mAPP appeared to depend on specific binding because the lung uptake was inhibited by excess unlabeled mAPP but not control mIgG (Fig. 6i).

At $16 \mathrm{~h}$ after injection, all antibodies except mAPP showed a strong thyroid signal and a substantial loss of lung signal, consistent with the deiodination known to occur in blood ${ }^{41}$ and a lack of accumulation and protection inside the lung tissue. Extended imaging of the distribution of mAPP from $5 \mathrm{~min}$ to $48 \mathrm{~h}$ after injection revealed a thyroid signal at $48 \mathrm{~h}$ but still a clear and strong lung image (Fig. 6m). High-resolution pinhole single photon-emission computed tomography (SPECT) imaging provided an even clearer three-dimensional visualization of this lung-specific targeting, including planar sections and rotating tomographic movies that showed the lung organ shape and heart cavity free of ${ }^{125} \mathrm{I}$-mAPP signal (arrowheads in Fig. 6j, k; Supplementary Video 4 and Supplementary Video 4 Legend online (30 min after injection), Supplementary Video 5 and Supplementary Video 5 Legend online (lung surface rendering at $30 \mathrm{~min}$ after injection) and Supplementary Video 6 and Supplementary Video 6 Legend online ( $48 \mathrm{~h}$ after injection)). Figure $7 \mathrm{a}-\mathrm{c}$ shows clear lung-specific imaging using dual modality SPECT/X-ray computed tomography (CT). Thus, mAPP rapidly (within minutes) and specifically targeted the lung to permit selective organ imaging in vivo that persisted for at least $2 \mathrm{~d}$ (Fig. 6m).

We quantified by region-of-interest analysis the imaged uptake in lung ( $1 \mathrm{~g}$ wet weight) over time, which confirmed that $\mathrm{mAPP}$ had the highest and most sustained accumulation in the lung (average of $78 \%$ of the injected dose per gram tissue (ID/g)), whereas the lung signal intensity for monoclonal antibodies mPodocalyxin (11\% ID/g), mCD34 (20\% ID/g), mACE (23\% ID/ g) and mPECAM (4\% ID/g) peaked within $1 \mathrm{~h}$ and decreased substantially thereafter (Fig. 6 and data not shown). Biodistribution analysis confirmed these results as well as mACE targeting of heart at $5 \% \mathrm{ID} / \mathrm{g}$ and quantified the mAPP lung uptake (which reached a maximum average of $77 \% \mathrm{ID} / \mathrm{g}$ within $30 \mathrm{~min})$, the minimal uptake in other organs $(<1 \% \mathrm{ID} / \mathrm{g})$ and the remarkably rapid clearance from the blood (Fig. 61). All targeting indices indicated specific, rapid and significant lung delivery, including at $1 \mathrm{~h}$, a mean tissue targeting index of 556 and tissue selectivity index of 39,180 as well as 446-fold more mAPP antibody in the lung than control mIgG (Supplementary Fig. 5 online).

To visualize lung accumulation more precisely, we again used both planar $\gamma$-scintigraphic and dual modality SPECT/X-ray CT imaging but this time with ${ }^{99 \mathrm{~m}} \mathrm{Tc}$-labeled mAPP. Dynamic planar imaging of rats immediately after intravenous injection of ${ }^{99 \mathrm{~m}} \mathrm{Tc}-\mathrm{mAPP}$ showed rapid binding of ${ }^{99 \mathrm{~m}} \mathrm{Tc}-\mathrm{mAPP}$ in lung that was essentially identical to the results of the ${ }^{125} \mathrm{I}$ dynamic studies in Figure 6a (data not shown). Dual SPECT/X-ray CT imaging showed intense ${ }^{99 \mathrm{~m} T c-}$ mAPP accumulation in the lung region as a 'speckled' pattern of highest-intensity radioactive signal comingled with regions of twofold-lower intensity (Fig. 7d-f). Higher magnification with intravascular contrast agents (Fig. 7f) showed that the speckled signal coincided with select segments of the vasculature beginning at the fifth or sixth branch point of the pulmonary artery (yellow dotted box). Immunostaining of lung tissue sections confirmed this segmental expression of APP by showing mAPP labeling only in smaller vessels starting at the fifth arterial branch point through to the microvessels, including capillaries, but not in the larger 
segments of the pulmonary artery (Supplementary Fig. 6 online). This imaging corresponds nicely with our intravital microscopy studies showing the strong endothelial cell-surface binding signal that creates an outline of the blood vessels sufficiently strong to be detected even in this imaging mode.

\section{DISCUSSION}

We have used subcellular fractionation and quantitative organellar proteomics to find a protein that is highly concentrated in caveolae, monoclonal antibody technology to generate specific targeting probes, and several in vivo imaging techniques to visualize and characterize caveolae targeting. Our results show that caveolae can mediate rapid, active transcellular transport within seconds of select cargo entry, a speed that rivals or exceeds that of transcytosis or endocytosis by clathrin-coated vesicles. Neither tissue-specific vascular targeting nor transendothelial transport by caveolae has been demonstrated previously by dynamic live imaging in vivo.

We used electron microscopy to confirm APP localization and mAPP targeting of caveolae of lung endothelium. Intravital microscopy provided dynamic live imaging of the antibody binding and crossing the lung vascular endothelium selectively to penetrate into the tissue within seconds to a minute after intravenous injection. Other antibodies to proteins not concentrated in caveolae bound the endothelial cell surface but did not cross the endothelial barrier. We also used gamma-scintigraphic planar imaging, SPECT and X-ray CT to evaluate lung immunotargeting at the whole-organ and body level. By comparing several new antibodies having different levels of specificity for lung endothelium, we showed that caveolae-targeting antibodies improve delivery and persist in the tissue for hours to days, whereas organ-targeting antibodies that do not bind caveolae can target effectively but only transiently. Thus, transcellular pumping by caveolae enhances delivery inside the tissue beyond standard vascular targeting.

Our 'in vivo proteomic imaging' approach—which integrates multiple imaging technologies with comparative, quantitative, organellar proteomic analysis - may assist in defining the in vivo accessible target space that is available to basic and clinical discovery efforts. A subset of this target space is the transvascular pumping space discerned from our caveolae experiments. This 'in vivo proteomic imaging' is more indirect than recent efforts to profile and image proteins directly in tissue sections by MALDI mass spectrometry 42 . Our approach identifies a large number of proteins in a small part of the tissue (subcellular fraction), whereas direct proteomic imaging interrogates more of the tissue but awaits expected technical advances to identify more and lower-abundance proteins.

Our experiments show that rapid transendothelial transport appears to depend on specific binding to APP concentrated in the lung endothelial caveolae. mAPP readily targets caveolae even when conjugated to 10- to 15-nm colloidal gold nanoparticles. As the accumulation of radiolabeled or fluorescent $\mathrm{mAPP}$ in the lung tissue is inhibited by excess unlabeled mAPP but not control $\mathrm{mIgG}$, this process appears to be saturable and specific. Even at low intravenous doses, the APP antibody becomes more concentrated at the endothelial cell surface and inside the tissue than in the blood. This transvascular exchange against a concentration gradient indicates active transport; diffusion would drive movement in the opposite direction. The control IgG experiments, showing no transport even at tenfold greater concentrations than mAPP, exclude transport driven by FcR or other IgG receptors and rule out any diffusive or convective paracellular or other nonspecific transvascular exchange mechanism. The experiments in which mAPP and control IgG are coinjected into the animal rule out random, nonspecific leakage in the blood vessels, even when examined at higher magnification. The lack of transendothelial transport of antibodies binding the endothelial cell surface but not in caveolae rules out a process dependent on general binding to the cell surface. 
The contrast between our results and previous in vitro studies that describe caveolae as immobile structures ${ }^{11-13}$ or as mediating slow endocytosis requiring $1-2 \mathrm{~h}^{8-10,43}$ is likely explained both by differences between in vivo and in vitro conditions and by the fact that $\mathrm{mAPP}$ binds caveolae directly, unlike most probes (viruses, antibodies, proteins) used previously, which enter caveolae only after extended sequestration (>30 min) on the cell surface. In this study, we found that the tissue interstitium is inundated with caveolae-targeted antibody by 1 min after injection. In a recent static imaging study performed in situ using electron microscopy ${ }^{14}$, we observed slower transendothelial transport of caveola-targeteing TX3.833 antibody conjugated to colloidal gold particles (10-15 min). Such differences in the observed transport rate highlight the importance of using live imaging. Dynamic live imaging is far superior to other methods, including tissue staining, for estimating relative uptake levels. A proper titration curve, determining signal range and sensitivity of tissue staining, is mandatory (but almost never performed) to ascertain both the degree of specificity in targeting and the proper linear dynamic range of the assay.

Our study also shows that antibodies to lung endothelial cell-surface proteins vary considerably in their targeting capability. Antibodies to APP, which is concentrated in caveolae, accumulate in the lung much more rapidly than antibodies to proteins not concentrated in caveolae.

Moreover, mAPP rapidly penetrates into the lung tissue and remains there for days, in contrast to the other antibodies. In removing ${ }^{125}$ I-labeled mAPP from constant exposure to the circulating blood, caveolae likely prevent antibody detachment from the luminal endothelial cell surface (enhanced by the convective flow and the falling blood concentration) and antibody dehalogenation from exposure to the blood (which frees the radio-iodine to yield a thyroid signal).

Unlike most epithelia, vascular endothelium maintains a very thinly stretched cell morphology. Except for regions near the nucleus, the two sides of the endothelial cell (luminal, exposed to the blood, and abluminal, exposed to the tissue interstitium) are $<150 \mathrm{~nm}$ apart. Thus, a single budded caveola moves only $\sim 70 \mathrm{~nm}$ or less to reach the other side of the cell. Caveolae in endothelium in vivo are abundant, occupying up to $60 \%$ of the cell surface membrane ${ }^{44}$, which far exceeds the $<1 \%$ seen for endothelial and other cells growing in vitro 7 . Lastly, the presence of key budding, docking and fusion proteins in caveolae $1,2,29,45,46$ may further enable rapid caveolar transcytosis observed in vivo. Apparently, unlike clathrin-coated pits, dynamin is oligomerized to coil around the invagination neck where it exists primed to hydrolyze GTP, forcing the dynamin spring to extend and 'pinch off' the caveolae from the plasma membrane ${ }^{1,2}$. Whether antibody binding to APP in caveolae induces signal-dependent budding of caveolae remains to be determined. Thus, it appears that both the microvascular endothelium and its caveolae are especially optimized for rapid, selective transvascular exchange through its caveolae.

Clinical translation of the caveolae-targeting strategy will require considerable efforts to create new retargeted therapeutics and imaging agents as well as to define which agents are amenable to delivery. It also remains to be determined whether select organs and diseases have specific caveolae targets. In the case of pulmonary disease, lung-specific agents are increasingly being pursued $^{25,26,47-49}$. Compared with other antibodies to endothelial cell-surface proteins (PECAM, ACE and podocalyxin), mAPP achieves more selective and rapid targeting to the lung. Podocalyxin antibody accumulates in multiple tissues, PECAM antibodies show targeting primarily in liver and lung, and ACE antibody targets lung, heart and possibly liver. APP expression has been reported in other cell types located inside tissue, such as the renal proximal tubule epithelium (Supplementary Fig. 3). But as antibodies are large macromolecules $(150 \mathrm{kDa})$ that do not readily cross the blood vessel wall, renal APP is effectively inaccessible to APP antibodies injected intravenously. The ability of caveolae- 
targeting antibodies to penetrate into lung tissue may allow delivery of therapeutic or reporter agents to regions where they will be more effective.

Because the lung is the only organ to receive nearly all of the cardiac output, the rapidity of lung uptake observed here may represent an extreme not possible in other organs. This, along with the first pass of the intravenous agent and the very large endothelial cell-surface area in the lung, is likely to contribute to substantial lung targeting even of antibodies to endothelial cell-surface proteins expressed in other organs (e.g., ACE, PECAM, podocalyxin). However, absolute tissue-restricted expression may not be required if these other contributing factors are absent in other tissues showing low-level target expression. Our comparison of multiple antibodies to endothelial cell-surface proteins expressed in lung suggests that the APP target possesses the advantages of direct accessibility, sufficient organ-specific endothelial expression and rapid caveolar transcytosis.

Caveolae appear to provide a strategic pathway worthy of targeting. They contain intravenously accessible, tissue-specific proteins that mediate active pumping into the tissue, overcoming the restrictive endothelial cell barrier. The caveolae gateway may therefore provide a selective, speedy shuttle service for imaging and therapeutic applications.

\section{METHODS}

\section{Antibodies}

Commercial mouse monoclonal antibodies recognizing caveolin-1 (clone 2234) (BD Biosciences), IgG (Southern Biotech), angiotensin-converting enzyme (Chemicon International), and PECAM (Santa Cruz Biotechnology) were purchased. Mouse monoclonal antibodies recognizing podocalyxin (G278, or mPodo), CD34 (mCD34) and APP (J310, TX3.833) were generated in house (Supplementary Data).

\section{Animals}

All animal experiments were carried out in accordance with protocols approved by the Institutional Animal Care and Use Committee (IACUC) of Sidney Kimmel Cancer Center (SKCC). Animals were housed in the SKCC animal care facility, and animals subjected to radio-iodine labeling were housed and imaged in a separate lead-protected animal facility of SKCC. Sprague-Dawley rats (150-250 g; Charles River Laboratories) were used unless indicated otherwise. Athymic, nude mice 8-9 weeks old were purchased from Harlan.

\section{Animal model and surgical techniques}

All surgical procedures were performed in a sterile laminar flow hood. Dorsal skin window chambers and surgical instruments were autoclaved before use. Saline used to keep tissue moist during surgical preparation was mixed with gentamicin $(50 \mu 1 / \mathrm{ml})$. The dorsal skin window chamber in the mouse was prepared as described ${ }^{50-52}$. Briefly, female mice (25-35 g body weight) were anesthetized ( $7.3 \mathrm{mg}$ ketamine hydrochloride and $2.3 \mathrm{mg}$ xylazine $/ 100 \mathrm{~g}$ body weight, i.p.) and placed on a heating pad. Two symmetrical titanium frames were implanted into a dorsal skinfold, to sandwich the extended double layer of skin. A $15 \mathrm{~mm}$ full thickness layer was excised. The underlying cutaneous maximus muscle and subcutaneous tissues were covered with a glass cover slip incorporated in one of the frames. Small circular Band-Aids were applied on the backside of the chamber after surgery to prevent scratching. After a recovery period of 1-2 d, lung tissue from a donor rat was minced and applied in the chamber. In previous experiments it was demonstrated using GFP-expressing graft tissue that the transplanted tissue revascularizes in 1-2 weeks with blood circulating through GFP-positive vessels of the original and not host tissue ${ }^{53}$. Also note that the mAPP is rat-specific and does 
not recognize mouse APP so that its positive reactivity with the endothelium confirms the rat tissue origin of the blood vessels.

For the lentiviral shRNA knockdown experiment, we used lentiviral transduction particles expressing either shRNA to rat caveolin-1 (MISSION shRNA TRCN0000008002, CCGGGACGTGGTCAAGATTGACTTTCTCGAGAAAGT

CAATCTTGACCACGTCTTTTT; BLAST search showed highest homology to rat caveolin-1 for this sequence) or control shRNA to human caveolin-1 (MISSION shRNA TRCN0000007999, CCGGGCTTTGTGATTCAATCTG TAACTCGAGTTACAGATTGAATCACAAAGCTTTTT; BLAST search showed no significant homology to any rat gene for this sequence) ${ }^{54}$.

\section{Intravital microscopy}

Fluorescence microscopy was performed using a Mikron Instrument Microscope (Mikron Instrument) equipped with epi-illuminator and video-triggered stroboscopic illumination from a xenon arc (X-400, PerkinElmer Optoelectronics). A silicon intensified target camera (SIT68, Dage-MTI) was attached to the microscope. A Hamamatsu image processor (Argus 20) with firmware version 2.50 (Hamamatsu Photonic System) was used for image enhancement. Video sequences were recorded to a computer using InterVideo WinDVR 3 to a computer equipped with an All-In-Wonder RADEON 9800 PRO Video Card. A Zeiss Achroplan $4 \times / 0.10$ objective was used to obtain an overview of the chamber to localize lung vessels. A Zeiss Achroplan $63 \mathrm{X} / 0.9 \mathrm{~W}$ objective was used for capturing video sequences of vessels in the grafted lung tissue.

\section{Analysis of intravital microscopy data}

Canopus Procoder version 2.0130.0 was used to convert video sequences into AVI format, and Adobe Premiere 6.5 was used to pseudo-color and edit the video sequences. Line profiles of fluorescence intensity of vessels of interest were obtained using Image_Pro Plus 5.1. The MPEG files were converted to AVI files using Canopus Procoder 2.0. Adobe Premiere 6.5 was used to reduce the number of frames to 200 for a $65 \mathrm{~s}$ interval. These sequences were then imported into ImagePro Plus 5.1, and rotated so that the vessel segment of interest was perpendicular to a horizontal thick line in the "line feature" in ImagePro Plus 5.1. The thickness of the line was chosen to be $5 \mu \mathrm{m}$. The signal intensity data of each line was imported into an Excel spread sheet which was imported into Matlab 7.0 to scale the dynamic range and then into SigmaPlot 2000 version 6.0 to scale colorimetrically and to create the graphic image. See Supplementary Methods online for details on image filtering.

\section{Whole body $\mathrm{Y}$-scintigraphic planar and single photon emission computed tomography (SPECT) imaging}

Antibodies were purified by Protein G chromatography (Pierce) and radiolabeled with ${ }^{125} \mathrm{I}$ using Iodobeads (Pierce) ${ }^{14}$. Anesthetized rats were injected via the tail vein with radiolabeled IgGs $(5 \mu \mathrm{g} ; 10 \mu \mathrm{Ci} / \mu \mathrm{g})$ alone or in the presence of unlabeled competitor IgG (30-fold molar excess). At various times after injection, planar images were captured (rats positioned ventrally facing the collimator) using a parallel-plate collimator fitted onto the A-SPECT system (Gamma Medica) ${ }^{55}$. For tomographic imaging, images were captured in $6^{\circ}$ increments for 64 frames ( $30 \mathrm{~s} /$ frame) using A-SPECT fitted with a parallel-plate or pin-hole collimator. For dynamic imaging, images were collected every second for $1 \mathrm{~min}$. X-SPECT was used for coupling SPECT with X-ray CT imaging. 


\section{9m Tc imaging}

mAPP was labeled with ${ }^{99} \mathrm{~m} \mathrm{Tc}$ (Supplementary Methods). Syringes were measured for activity before and after injection using an Atomlab 100 dose calibrator (Biodex Medical Systems). Anesthetized Lewis male rats were injected via the tail vein with $16.7 \mu \mathrm{g}$ of ${ }^{99 \mathrm{~m}} \mathrm{Tc}-\mathrm{mAPP}$ and imaged by static planar techniques, with at least 50,000 total counts per image collected. Images were processed with a modified version of NIH Image (NucMed_Image, Mark D. Wittry, St. Louis University, St. Louis, MO, USA) using standard manual region of interest analyses drawn to include only the lung area. Dual modality SPECT and X-ray computed tomography (CT) images were collected using the A-SPECT system with an integrated microCT (GammaMedica). For the SPECT series, a total of 64 individual images (30 s/image) were collected using a $1 \mathrm{~mm}$ pinhole collimator. Each X-ray CT series included 256 views; one series was collected without contrast, while a second was collected at $20 \mathrm{~s}$ after IV injection of $0.5 \mathrm{ml}$ iohexol (Omnipaque, Amersham Health). The reconstructed SPECT and X-ray CT images were fused to allow precise localization of ${ }^{99 \mathrm{~m}} \mathrm{Tc}-\mathrm{mAPP}$. Images presented with SPECT-X-ray CT overlays represent $1.0 \mathrm{~mm}$ slices.

\section{Supplementary Material}

Refer to Web version on PubMed Central for supplementary material.

\section{Acknowledgements}

We thank Alexina Wempren, Michelle Bourne, Lisa Pang, Dale Winger and Traci Smith for technical assistance. This research was supported by funds provided in part by National Institutes of Health grants R01 HL52766, R01 HL58216, R01 HL074063, R24CA95893 and PO1CA104898 and by the Tobacco-Related Disease Research Program, grant number 11RT-0167.

\section{References}

1. Schnitzer JE, Oh P, McIntosh DP. Role of GTP hydrolysis in fission of caveolae directly from plasma membranes. Science [publisher's erratum appears in Science 1996 Nov 15;274(5290):1069] 1996;274:239-242.

2. Oh P, McIntosh DP, Schnitzer JE. Dynamin at the neck of caveolae mediates their budding to form transport vesicles by GTP-driven fission from the plasma membrane of endothelium. J Cell Biol 1998;141:101-114. [PubMed: 9531551]

3. Razani B, et al. Caveolin-1 null mice are viable but show evidence of hyperproliferative and vascular abnormalities. J Biol Chem 2001;276:38121-38138. [PubMed: 11457855]

4. Drab M, et al. Loss of caveolae, vascular dysfunction, and pulmonary defects in caveolin-1 genedisrupted mice. Science 2001;293:2449-2452. [PubMed: 11498544]

5. Durr E, et al. Direct proteomic mapping of the lung microvascular endothelial cell surface in vivo and in cell culture. Nat Biotechnol 2004;22:985-992. [PubMed: 15258593]

6. Oh P, et al. Subtractive proteomic mapping of the endothelial surface in lung and solid tumours for tissue-specific therapy. Nature 2004;429:629-635. [PubMed: 15190345]

7. Schnitzer JE, Carley WW, Palade GE. Specific albumin binding to microvascular endothelium in culture. Am J Physiol 1988;254:H425-H437. [PubMed: 3279821]

8. Parton RG. Ultrastructural localization of gangliosides; GM1 is concentrated in caveolae. J Histochem Cytochem 1994;42:155-166. [PubMed: 8288861]

9. Pelkmans L, Kartenback J, Helenius A. Caveolar endocytosis of Simian virus 40 reveals a novel twostep vesicular transport pathway to the ER. Nat Cell Biol 2001;3:473-483. [PubMed: 11331875]

10. Schnitzer JE, Oh P, Pinney E, Allard J. Filipin-sensitive caveolae-mediated transport in endothelium: reduced transcytosis, scavenger endocytosis, and capillary permeability of select macromolecules. $\mathrm{J}$ Cell Biol 1994;127:1217-1232. [PubMed: 7525606] 
11. Thomsen P, Roepstorff K, Stahlhut M, van Deurs B. Caveolae are highly immobile plasma membrane microdomains, which are not involved in constitutive endocytic trafficking. Mol Biol Cell 2002;13:238-250. [PubMed: 11809836]

12. Severs NJ. Caveolae: static inpocketings of the plasma membrane, dynamic vesicles or plain artifact? J Cell Sci 1988;90:341-348. [PubMed: 3075612]

13. Bundgaard M, Frokjaer-Jensen J, Crone C. Endothelial plasmalemmal vesicles as elements in a system of branching invaginations from the cell surface. Proc Natl Acad Sci USA 1979;76:6439-6442. [PubMed: 316540]

14. McIntosh DP, Tan XY, Oh P, Schnitzer JE. Targeting endothelium and its dynamic caveolae for tissue-specific transcytosis in vivo: A pathway to overcome cell barriers to drug and gene delivery. Proc Natl Acad Sci USA 2002;99:1996-2001. [PubMed: 11854497]

15. Simionescu M, Simionescu N, Palade GE. Morphometric data on the endothelium of blood capillaries. J Cell Biol 1974;60:128-152. [PubMed: 4129076]

16. Simionescu M, Simionescu N. Endothelial transport of macromolecules: transcytosis and endocytosis. A look from cell biology. Cell Biol Rev 1991;25:1-78. [PubMed: 1764617]

17. Carver LA, Schnitzer JE. Caveolae: mining little caves for new cancer targets. Nat Rev Cancer 2003;3:571-581. [PubMed: 12894245]

18. Schnitzer JE. Update on the cellular and molecular basis of capillary permeability. Trends Cardiovasc Med 1993;3:124-130.

19. Jain RK. The next frontier of molecular medicine: delivery of therapeutics. Nat Med 1998;4:655657. [PubMed: 9623964]

20. Herschman HR. Molecular imaging: looking at problems, seeing solutions. Science 2003;302:605608. [PubMed: 14576425]

21. Rudin M, Weissleder R. Molecular imaging in drug discovery and development. Nat Rev Drug Discov 2003;2:123-131. [PubMed: 12563303]

22. Tomlinson E. Theory and practice of site-specific drug delivery. Adv Drug Deliv Rev 1987;1:87198.

23. Dvorak HF, Nagy JA, Dvorak AM. Structure of solid tumors and their vasculature: implications for therapy with monoclonal antibodies. Cancer Cells 1991;3:77-85. [PubMed: 1711364]

24. Schnitzer JE. Vascular targeting as a strategy for cancer therapy. N Engl J Med 1998;339:472-474. [PubMed: 9700184]

25. Jenkins RG, McAnulty RJ, Hart SL, Laurent GJ. Pulmonary gene therapy. Realistic hope for the future, or false dawn in the promised land? Monaldi Arch Chest Dis 2003;59:17-24. [PubMed: 14533278]

26. Courrier HM, Butz N, Vandamme TF. Pulmonary drug delivery systems: recent developments and prospects. Crit Rev Ther Drug Carrier Syst 2002;19:425-498. [PubMed: 12661699]

27. Kozower BD, et al. Immunotargeting of catalase to the pulmonary endothelium alleviates oxidative stress and reduces acute lung transplantation injury. Nat Biotechnol 2003;21:392-398. [PubMed: 12652312]

28. Burrows FJ, Thorpe PE. Vascular targeting-a new approach to the therapy of solid tumors. Pharmacol Ther 1994;64:155-174. [PubMed: 7846113]

29. Schnitzer JE. Caveolae: from basic trafficking mechanisms to targeting transcytosis for tissue-specific drug and gene delivery in vivo. Adv Drug Deliv Rev 2001;49:265-280. [PubMed: 11551399]

30. Carver, LA.; Schnitzer, JE. Tissue-specific pharmacodelivery and overcoming key cell barriers in vivo: Vascular targeting of caveolae. In: Muzykantov, V.; Torchilin, B., editors. Biomedical Aspects of Drug Targeting. Kluwer Academic Publishers; Boston: 2002. p. 107-128.

31. Denekamp J. Vasculature as a target for tumour therapy. Progr Appli Microcirc 1984;4:28-38.

32. Schnitzer, JE. The endothelial cell surface and caveolae in health and disease. In: Born, G.; Shwartz, CJ., editors. Vascular Endothelium: Physiology, Pathology, and Therapeutic Opportunities. Schattauer; Stuttgart: 1997. p. 77-95.

33. Carver, LA.; Schnitzer, JE. Proteomic mapping of endothelium and vascular targeting in vivo. In: Aird, W., editor. Endothelial Biomedicine. 2007. p. 881-897.In press 
34. Pasqualini R, Ruoslahti E. Organ targeting in vivo using phage display peptide libraries. Nature 1996;380:364-366. [PubMed: 8598934]

35. Muzykantov VR, et al. Streptavidin facilitates internalization and pulmonary targeting of an antiendothelial cell antibody (platelet-endothelial cell adhesion molecule 1): a strategy for vascular immunotargeting of drugs. Proc Natl Acad Sci USA 1999;96:2379-2384. [PubMed: 10051650]

36. Hughes BJ, Kennel SK, Lee R, Huang L. Monoclonal antibody targeting of liposomes to mouse lung in vivo. Cancer Res 1989;49:6214-6220. [PubMed: 2478282]

37. Schnitzer JE, McIntosh DP, Dvorak AM, Liu J, Oh P. Separation of caveolae from associated microdomains of GPI-anchored proteins. Science 1995;269:1435-1439. [PubMed: 7660128]

38. Oh, P.; Schnitzer, JE. Isolation and subfractionation of plasma membranes to purify caveolae separately from glycosyl-phospatidylinositol-anchored protein microdomains. In: Celis, J., editor. Cell Biology: A laboratory handbook. Academic Press; 1998. p. 34-46.

39. Oh P, Schnitzer JE. Immunoisolation of caveolae with high affinity antibody binding to the oligomeric caveolin cage: toward understanding the basis of purification. J Biol Chem 1999;274:23144-23154. [PubMed: 10438484]

40. Muro H, Shirasawa H, Maeda M, Nakamura S. Fc receptors of liver sinusoidal endothelium in normal rats and humans. A histology study with soluble immune complexes. Gastroenterology 1987;93:1078-1085. [PubMed: 3308622]

41. Russell J, et al. Iodination of annexin V for imaging apoptosis. J Nucl Med 2002;43:671-677. [PubMed: 11994533]

42. Chaurand P, Sanders ME, Jensen RA, Caprioli RM. Proteomics in diagnostic pathology: profiling and imaging proteins directly in tissue sections. Am J Pathol 2004;165:1057-1068. [PubMed: 15466373]

43. Nichols BJ, et al. Rapid cycling of lipid raft markers between the cell surface and Golgi complex. J Cell Biol 2001;153:529-541. [PubMed: 11331304]

44. Porter GA, Bankston PW. Maturation of myocardial capillaries in the fetal and neonatal rat: an ultrastructural study with a morphometric analysis of the vesicle populations. Am J Anat 1987;178:116-125. [PubMed: 3578075]

45. Schnitzer JE, Liu J, Oh P. Endothelial caveolae have the molecular transport machinery for vesicle budding, docking, and fusion including VAMP, NSF, SNAP, annexins, and GTPases. J Biol Chem 1995;270:14399-143404. [PubMed: 7782301]

46. McIntosh DP, Oh P, Schnitzer JE. Caveolae require intact VAMP-2 for targeted transport in vascular endothelium. Am J Physiol 1999;277:H2222-H2232. [PubMed: 10600840]

47. Miller N, Vile R. Targeted vectors for gene therapy. FASEB J 1995;9:190-199. [PubMed: 7781922]

48. Galanis E, Vile R, Russell SJ. Delivery systems intended for in vivo gene therapy of cancer: targeting and replication competent viral vectors. Crit Rev Oncol Hematol 2001;38:177-192. [PubMed: 11369253]

49. Bilbao G, Gomez-Navarro J, Curiel DT. Targeted adenoviral vectors for cancer gene therapy. Adv Exp Med Biol 1998;451:365-374. [PubMed: 10026898]

50. Lehr HA, Leunig M, Menger MD, Nolte D, Messmer K. Dorsal skinfold chamber technique for intravital microscopy in nude mice. Am J Pathol 1993;143:1055-1062. [PubMed: 7692730]

51. Alger GH. An adaptation of the transparent chamber technique to the mouse. J Natl Cancer Inst 1943;4:1-11.

52. Frost GI, Borgstrom P. Real time in vivo quantitation of tumor angiogenesis. Methods Mol Med 2003;85:65-78. [PubMed: 12710198]

53. Frost GI, et al. Novel syngeneic pseudo-orthotopic prostate cancer model: vascular, mitotic and apoptotic responses to castration. Microvasc Res 2005;69:1-9. [PubMed: 15797254]

54. Moffat J, et al. A Lentiviral RNAi Library for Human and Mouse Genes Applied to an Arrayed Viral High-Content Screen. Cell 2006;124:1283-1298. [PubMed: 16564017]

55. McElroy D, et al. Performance evaluation of A-SPECT: A high resolution desktop pinhole SPECT system for imaging small animals. IEEE Trans Nucl Sci NS 2002;49:2139-2147. 
a

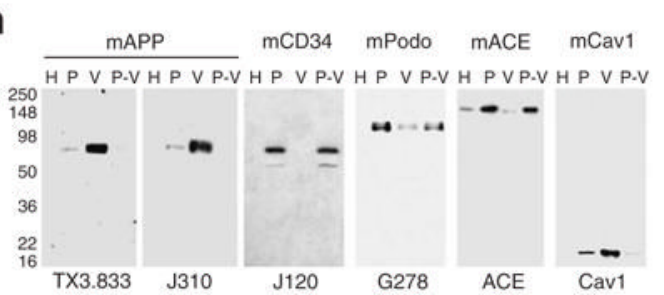

C

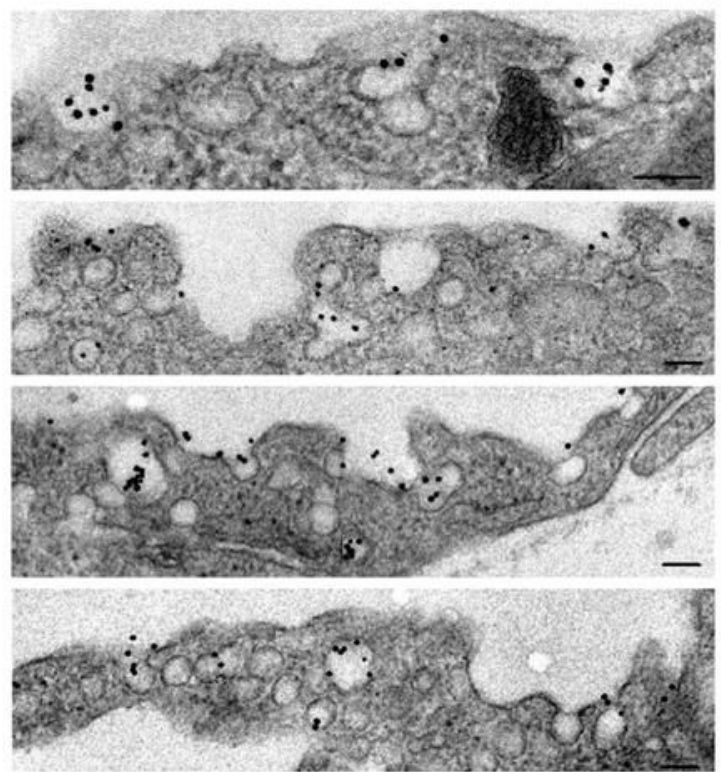

b
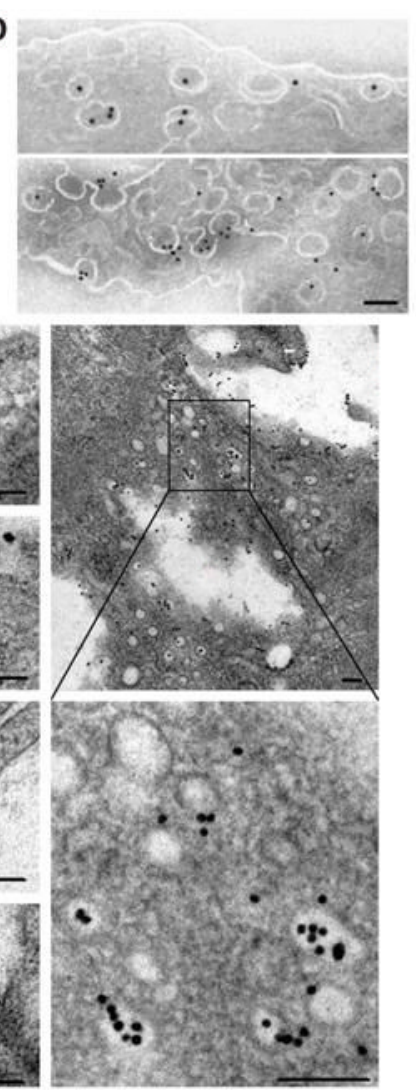

Figure 1.

Antibody targets caveolae rich in APP. (a) Western blot analysis of subfractionated lung tissue shows that APP is highly enriched in caveolae, whereas CD34 appears excluded from caveolae. Tissue fractions were probed with monoclonal antibodies to APP (TX3.833, J310), CD34 (mCD34), podocalyxin (mPodo) and angiotensin-converting enzyme (mACE). H, wholeorgan homogenate; $\mathrm{P}$, silica-coated luminal endothelial plasma membranes; V, caveolae; P-V, resedimented P stripped of caveolae. (b,c) EM of ultra-thin cryosection of lung tissue stained with mAPP (b) and secondary gold-labeled antibody. (c) EM of lung microvascular endothelium after pulmonary artery perfusion of two separate rats, showing mAPP goldnanoparticles targeting caveolae. Lung tissue from rat no. 1 is shown in bottom two plates, left column. Tissue from rat no. 2 is shown in upper two plates, left column and two plates, right column (see Supplementary Methods for details). Scale, $100 \mathrm{~nm}(\mathbf{b}, \mathbf{c})$. 

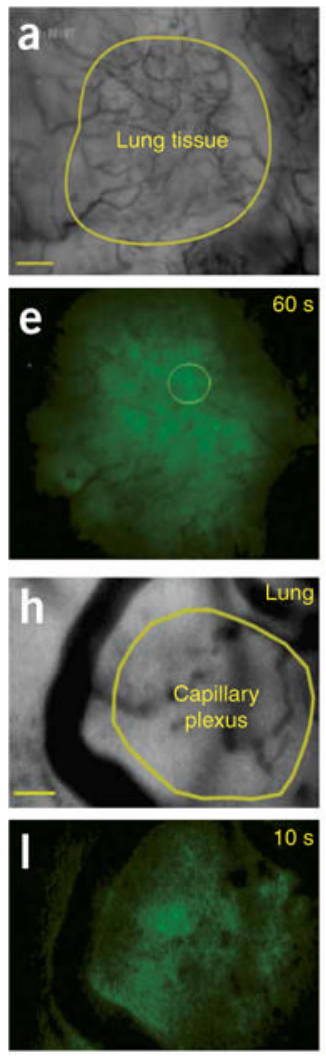
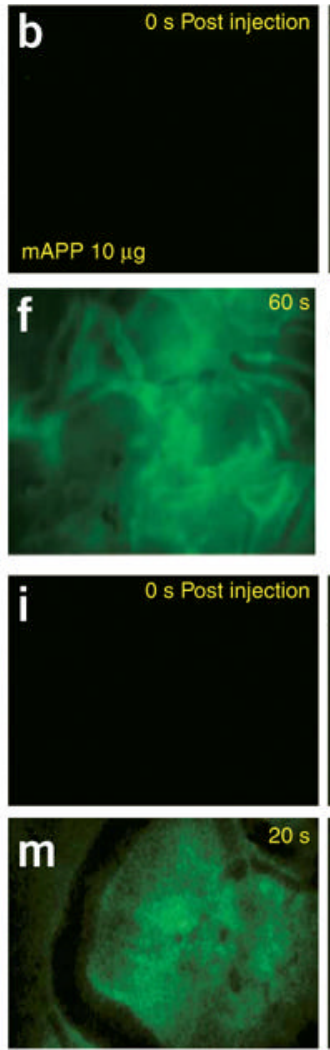
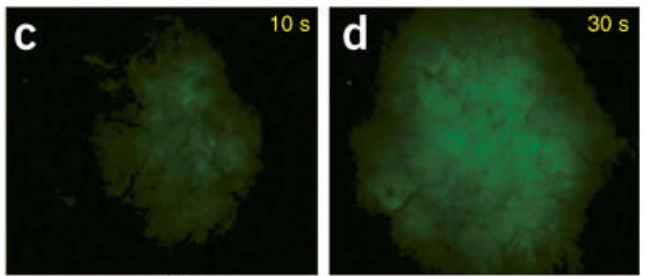

g
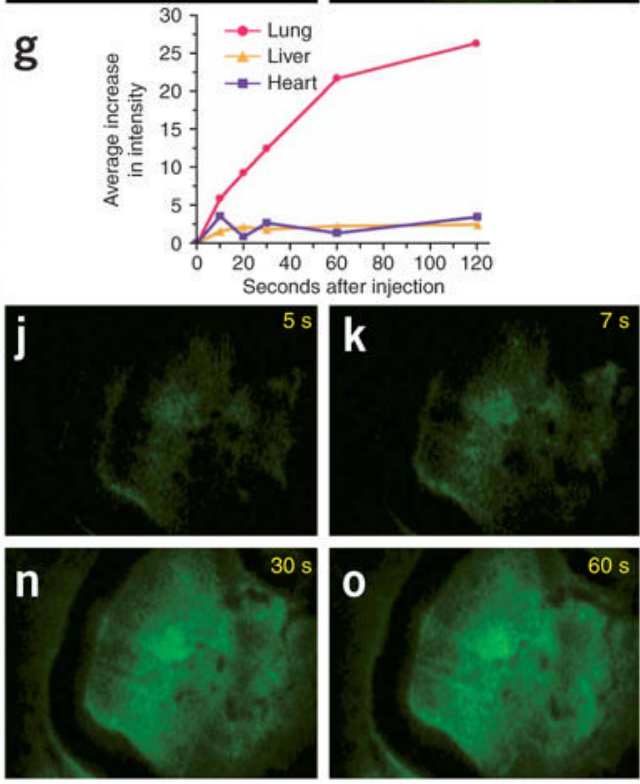

Figure 2.

Imaging rapid mAPP targeting and uptake in lung tissue using intravital fluorescence microscopy. Athymic nude mice with organ tissue implanted in dorsal skin window chambers were injected through the tail vein with mAPP conjugated to fluorophore Alexa A488 (mAPP-488) $(\mathbf{a}-\mathbf{g}(10 \mu \mathrm{g})$ and $\mathbf{h}-\mathbf{o}(1 \mu \mathrm{g}))$. (a) Low-magnification phase image of the lung tissue (yellow outline) implanted in surrounding skin. Note the more extensive vasculature in the lung tissue versus the skin. (b-f) Images of fluorescence detected in lung but not skin tissue at the indicated times after injection. Higher magnification of fluorescence detected at $60 \mathrm{~s}$ (f), showing the yellow circled region in e. (g) The relative intensity of mAPP-A488 fluorescence in engrafted lung, heart and liver tissue, graphed relative to the time after injection. (h) Higher-magnification phase image of implanted lung tissue showing capillary-rich region (yellow outline). (i-o) Fluorescence imaging of lung tissue at the times indicated after injection showing microvessel wall labeling and rapid accumulation in capillary plexus. Scale bar, 200 $\mu \mathrm{m}(\mathbf{a}-\mathbf{e}) ; 40 \mu \mathrm{m}(\mathbf{f}) .20 \mu \mathrm{m},(\mathbf{h}-\mathbf{o})$. 

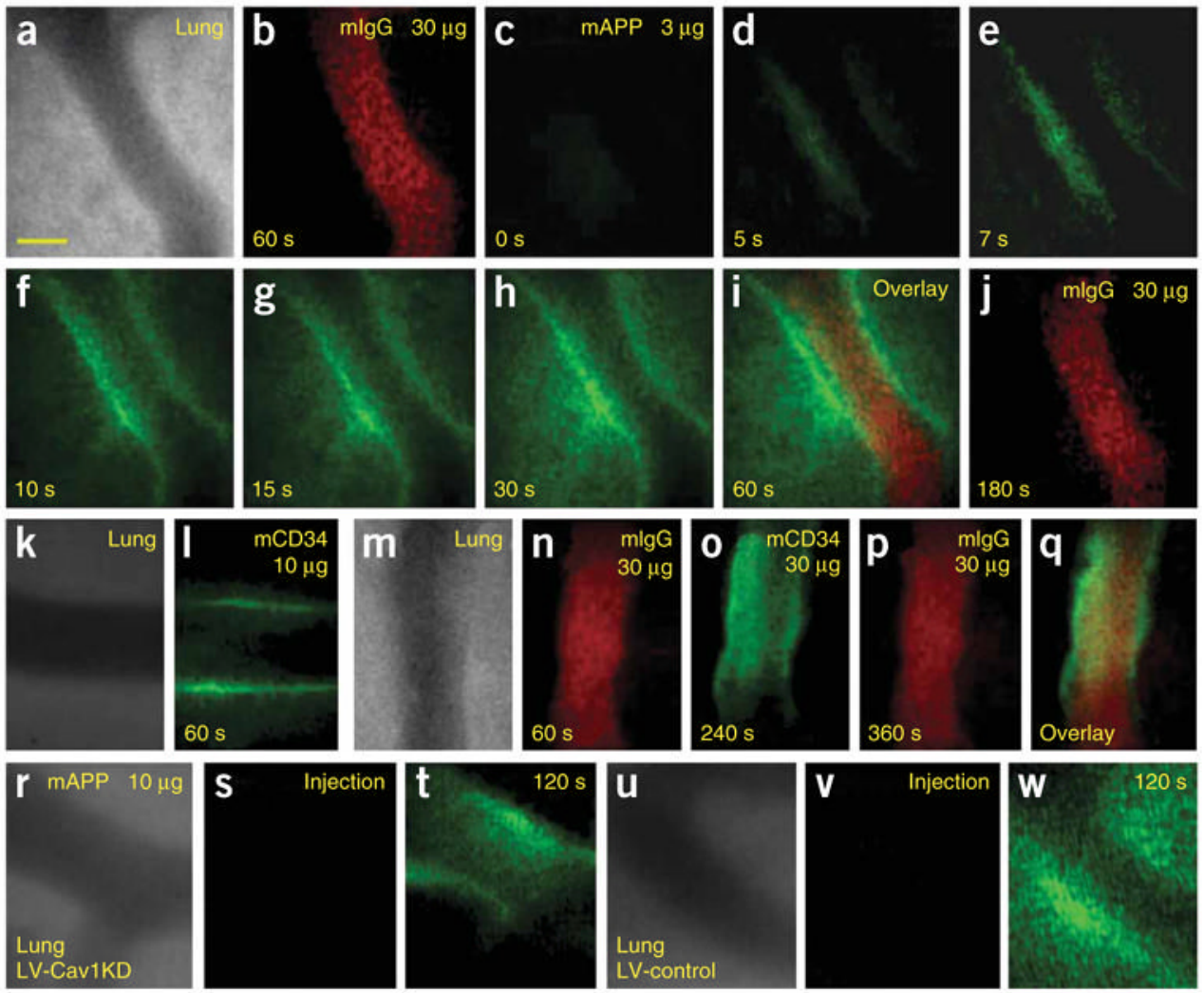

Figure 3 .

High-magnification intravital fluorescence microscopy of solitary lung microvessels. Athymic nude mice with implanted lung tissue were injected through the tail vein with indicated fluorophore-labeled antibody ( $30 \mu \mathrm{g}$ of control antibody, mIgG-A568, followed 1 min later with $3 \mu \mathrm{g}$ mAPP-A488). (a) Phase-contrast image of microvessel without other vessels nearby. (b) Fluorescence imaging of mIgG-A568 $60 \mathrm{~s}$ after injection showing ample intravessel signal but no detectable extravasation. (c-h) Fluorescence imaging at the indicated times after mAPPA488 injection. Note the low injected dose produces minimal intravessel signal, yet progressively concentrated signal first at the endothelial cell surface and then within the perivascular space inside the tissue. (i) Coregistered dual fluorescence image taken $125 \mathrm{~s}$ after mIgG-A568 injection and $60 \mathrm{~s}$ after mAPP-A488 injection. (j) Imaging of control mIgG-A568 at $180 \mathrm{~s}$ after injection shows signal in the microvessel lumen but not in the tissue interstitium. (k) Phase-contrast image of microvessel without other vessels nearby. (l,n-q) Fluorescence imaging of mCD34 and $\mathrm{mIgG}$ controls at the injected dose and post-injection times indicated. Note clear endothelial cell-surface binding with mCD34 even at low dose where circulating signal inside the vessel is minimal. Even at higher dose no extravasation of mCD34 or mIgG is detected. (m) Phase-contrast image of microvessel without other vessels nearby. (q) Coregistered image of $\mathbf{o}$ and $\mathbf{p}$ shows $\mathrm{mCD} 34$ vessel wall binding lacks $\mathrm{mIgG}$ signal. (r-w) Rat lung tissue, infected with lentivirus expressing either shRNA specific to rat caveolin-1 $(\mathbf{r}-\mathbf{t})$, or control shRNA (u-w), was implanted into the dorsal skin window chambers of athymic nude mice, which were injected intravenously with $10 \mu \mathrm{g}$ mAPP-A488 before fluorescence imaging at $0(\mathbf{s}, \mathbf{t})$ and $120 \mathrm{~s}(\mathbf{t}, \mathbf{w})$ after injection. Phase-contrast image of microvessel without other vessels nearby $(\mathbf{r}, \mathbf{u})$. Scale bar, $20 \mu \mathrm{m}$. 

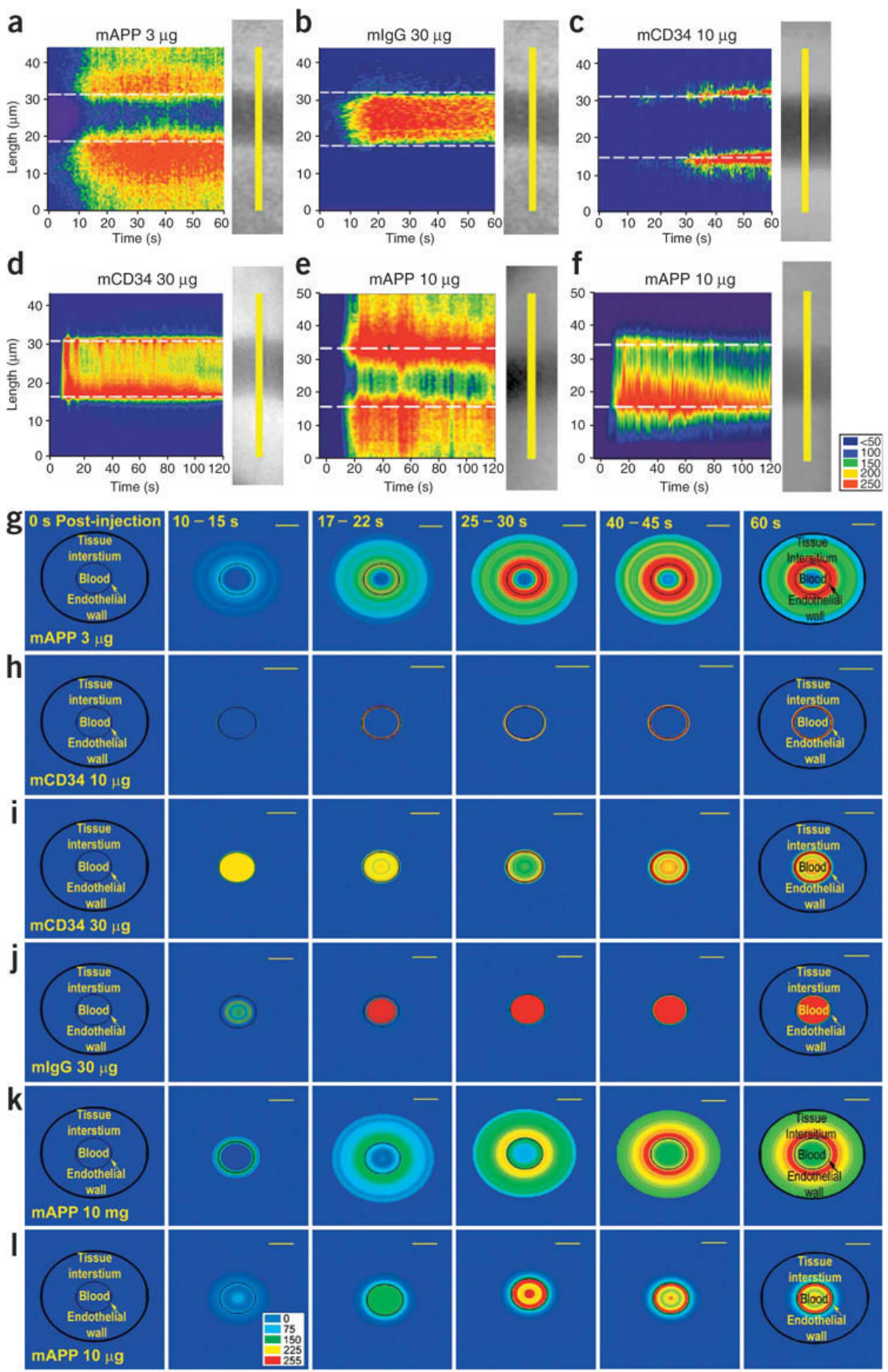

Figure 4.

Digital analysis of fluorescence imaging in lung tissue to assess antibody transport in lung tissue. Digital images from intravital fluorescence microscopy of lung tissue implanted in dorsal skin window chamber were collected at three frames/s for 1-2 min after intravenous injection of the indicated fluorophore-labeled antibody. (a,f) Signal intensity time-space profiles. The fluorescence signal was measured in each digital image specifically in the pixels corresponding to the yellow line in the phase image showing the blood vessel and perivascular space. This detected signal intensity is plotted in pseudo-color (see colorimetric scale) as a function of time and tissue location (length in $\mu \mathrm{m}$ from the bottom of the yellow line). The dashed white line corresponds to the edge of the vessel wall. (g-l) Polar plots of processed 
fluorescence images in tissue cross-section. The fluorescence intensities as measured above were converted to polar coordinates using the central axis of the blood microvessel as the zero reference point. The average intensity from five measurements for each antibody is shown in pseudo-color (see colorimetric scale) at the post-injection times indicated. The black circle indicates the outer border of the tissue space examined and the thin lined smaller circle delineates the blood-endothelial cell interface. Standard lung tissue $(\mathbf{a}-\mathbf{d}, \mathbf{g}-\mathbf{j})$; lung tissue infected with control lentivirus $(\mathbf{e}, \mathbf{k})$ or with lentivirus to knock down caveolin-1 expression (f,I). Note that the time scales for a-f vary from 0 to 60 or 120 s. Scale bars, $20 \mu \mathrm{m}$. 

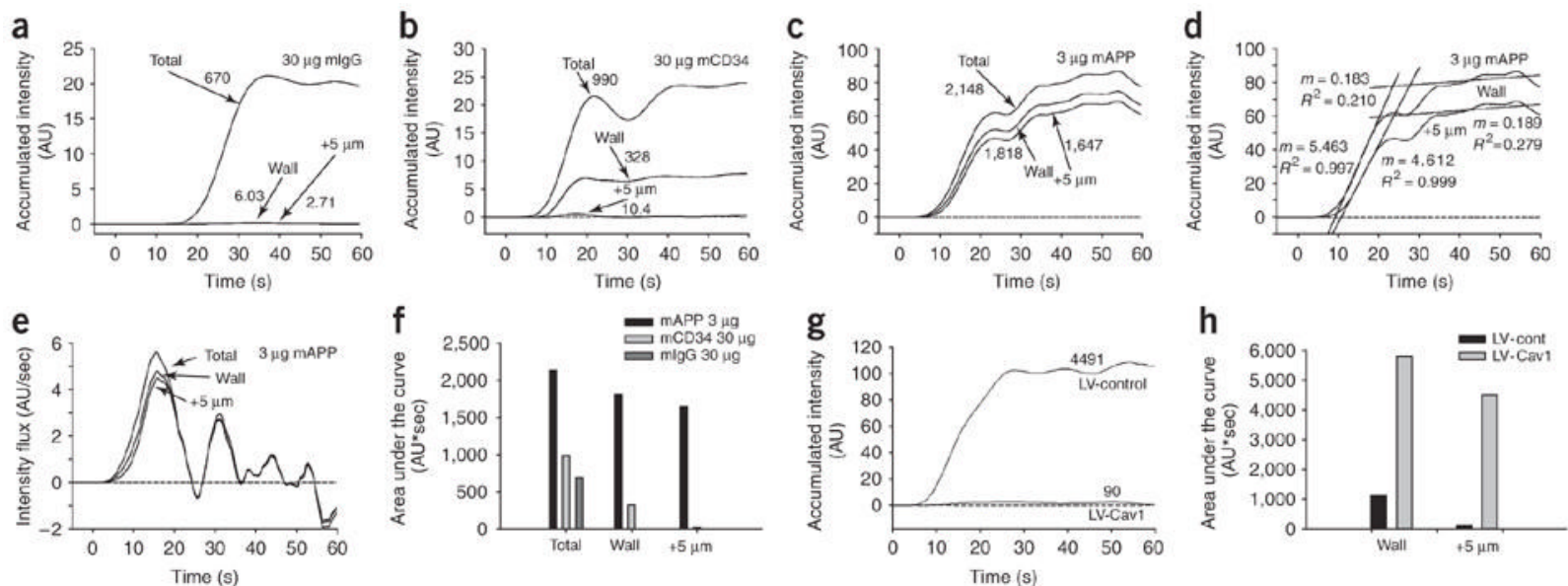

Figure 5.

Quantifying relative uptake, transport and flux of antibodies in lung tissue. (a-d) Tissue accumulated intensity curves for the indicated antibodies were determined from the polar plots (Fig. 4). The 'Total' represents analysis of intensity from the center of the blood vessel to the outermost point analyzed or the total cumulative signal intensity in the whole observation space. The 'Wall' represents analysis of intensity from the blood vessel wall to the outermost point analyzed (intravessel signal subtracted). The ' $+5 \mu \mathrm{m}$ ' curve graphs the cumulative intensity starting $5 \mu \mathrm{m}$ beyond the blood vessel wall into the tissue interstitium. The numbers next to each curve indicate the area under each curve for the $60 \mathrm{~s}$ period. Accumulated intensity of mAPP over time at the 'Wall' and at ' $+5 \mu \mathrm{m}$ ' with linear regression fitting to estimate flux (d). (e) Instantaneous flux determined by derivatives taken at each time point for each curve in (d). (f) Determining area under the curves in panels a-c by integrating signal versus time curves over $60 \mathrm{~s}$. (g) Cumulative intensity starting $5 \mu \mathrm{m}$ beyond the blood vessel wall into the tissue interstitium (' $+5 \mu \mathrm{m}$ ') with control lentiviral shRNA (LV-Control) and rat caveolin-1 shRNA (LV-Cav1). (h) Determining area under the curve by integrating signal versus time curves for both 'Wall' and ' $+5 \mu \mathrm{m}$ ' over $60 \mathrm{~s}$ in lung tissue with lentiviral caveolin shRNA (LV-Cav1) and LV-Control. 
a
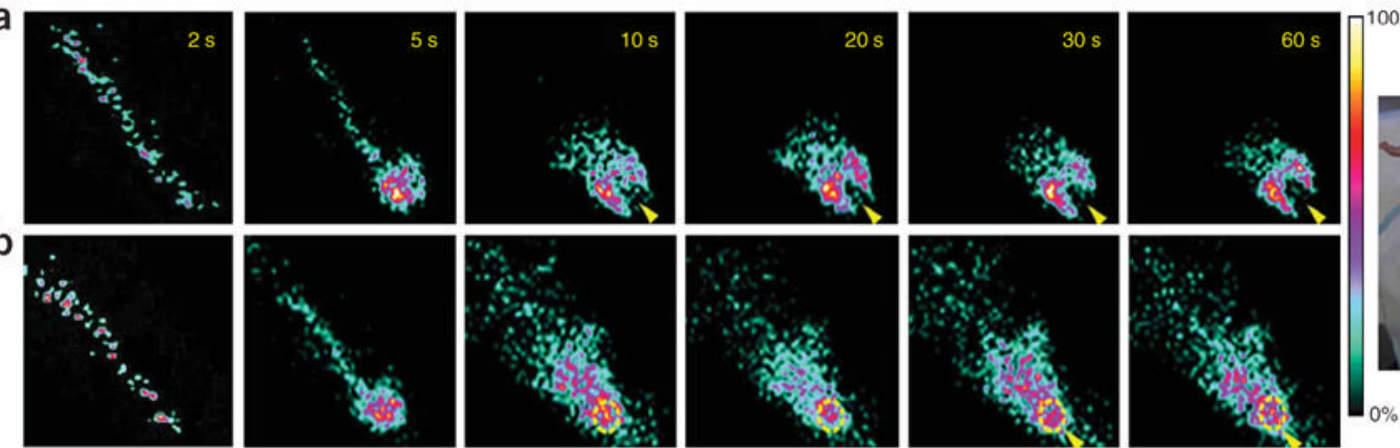

C
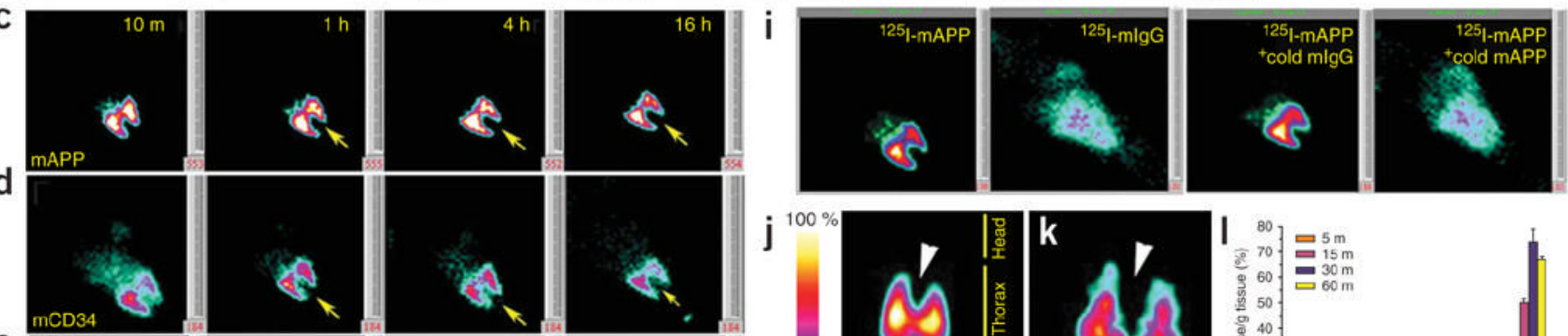

e
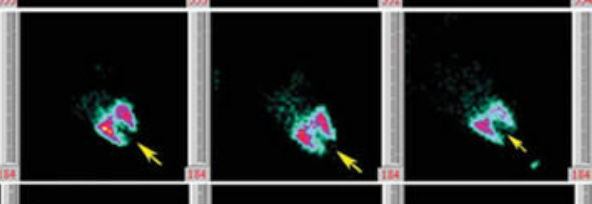

$\mathbf{j}^{100}$
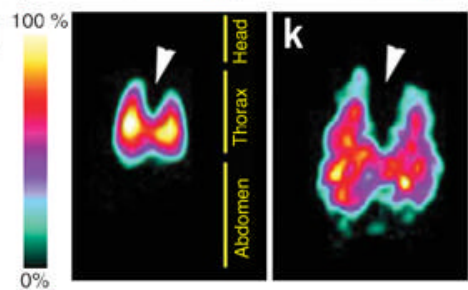

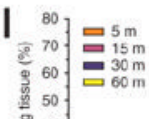
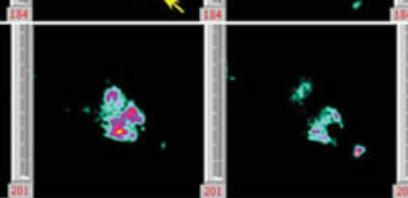

f
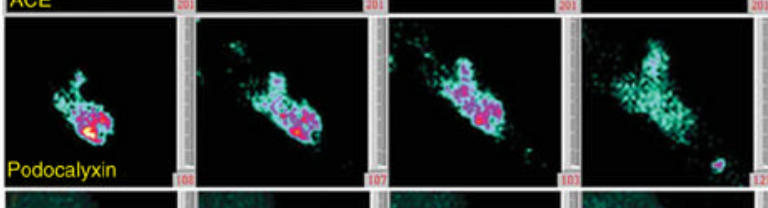

m

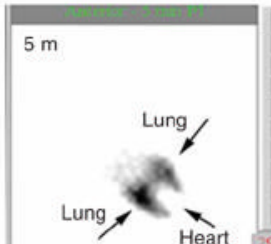

g
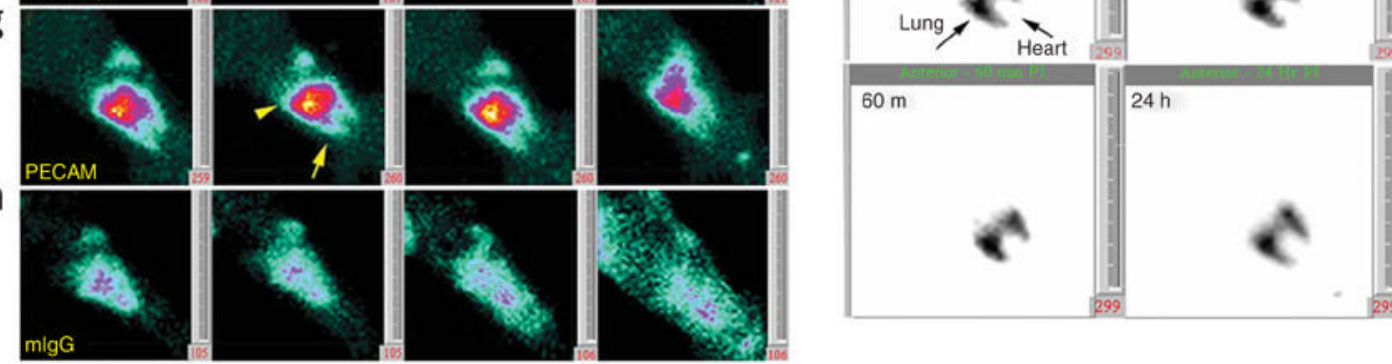

Thyroid $\rightarrow e$

Figure 6.

Dynamic and planar $\gamma$-scintigraphic live imaging of rapid lung immunotargeting in vivo. Rats were injected through the tail vein with ${ }^{125}$ I-labeled antibodies $(10 \mu \mathrm{g}$ at $10 \mu \mathrm{Ci} / \mu \mathrm{g}$ unless otherwise stated). (a,b) Rats were imaged at $1 \mathrm{~s}$ intervals for 1 min immediately after injection with ${ }^{125} \mathrm{I}-\mathrm{mAPP}$ (a) or ${ }^{125} \mathrm{I}-\mathrm{mIgG}$ (b) $(20 \mu \mathrm{g}, 10 \mu \mathrm{Ci} / \mu \mathrm{g})$ as indicated. Representative static frames captured at the indicated times show rapid specific accumulation of mAPP within the rat lung. Arrowheads denote heart-shaped cavity rendered apparent by lack of signal in bloodengorged heart and strong signal in lung. Dotted yellow circle shows heart position with significant signal from control IgG circulating through blood-engorged heart. Photo, right panel, shows orientation of the rat during imaging. (c-i) Planar gamma-scintigraphic images of rats at the indicated post-injection time for ${ }^{125} \mathrm{I}-\mathrm{mAPP}$ injection (c), ${ }^{125} \mathrm{I}-\mathrm{mCD} 34$ (d), ${ }^{125} \mathrm{I}$ mACE (e), ${ }^{125} \mathrm{I}$-mPodo (f), ${ }^{125} \mathrm{I}$-mPECAM (g) or ${ }^{125} \mathrm{I}$-mIgG (h). In $\mathbf{c}$ and $\mathbf{d}$ arrow indicates position of heart cavity. In (g), arrow denotes lung accumulation; arrowhead denotes liver accumulation. Planar $\gamma$-scintigraphic images of rats $30 \mathrm{~min}$ after injection of ${ }^{125} \mathrm{I}$ mAPP, ${ }^{125} \mathrm{I}-\mathrm{mIgG}$ or ${ }^{125} \mathrm{I}$-mAPP plus 30 -fold excess of unlabeled $\mathrm{mIgG}$ or mAPP as indicated 
(i). (j,k) Images from planar $\gamma$-scintigraphy, collected 30 min after injection of ${ }^{125}$ I-mAPP, showing accumulation of mAPP in the lung (a parallel-plate collimator was used in $\mathbf{j}$ and a high resolution pinhole collimator in $\mathbf{k}$ ). Orientation of rat is indicated. Arrowhead denotes heart cavity. (l) Blood levels and tissue uptake of ${ }^{125} \mathrm{I}-\mathrm{mAPP}$ at the indicated times after injection. (m) Planar $\gamma$-scintigraphic images of rats injected with ${ }^{125} \mathrm{I}$-mAPP captured at the indicated time post-injection. Pseudocolor scale in (j) serves all images in $(\mathbf{c}-\mathbf{k})$. For presentation purposes, the ${ }^{125}$ I-Podocalyxin antibody (G278) and ${ }^{125} \mathrm{I}-\mathrm{mIgG}$ signals were multiplied about fivefold, ${ }^{125}$ I-PECAM antibody elevated twofold and ${ }^{125} \mathrm{I}-\mathrm{mCD} 34$ and ${ }^{125} \mathrm{I}-$ ACE antibody elevated threefold. The number in the bottom right corner of each image indicates dynamic intensity scale range of the given image starting at 0 to $100 \%$ as per color scale shown next to (j). For a setting of 500, a yellow/white signal indicative of $100 \%$ will be fivefold greater than the same color achieved at a setting of 100 . 
a

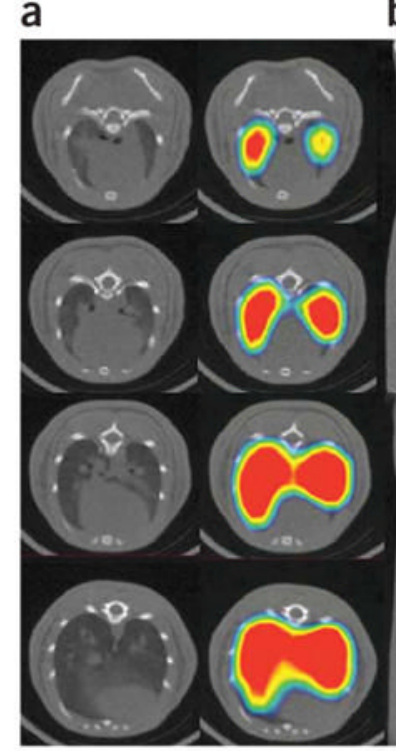

d

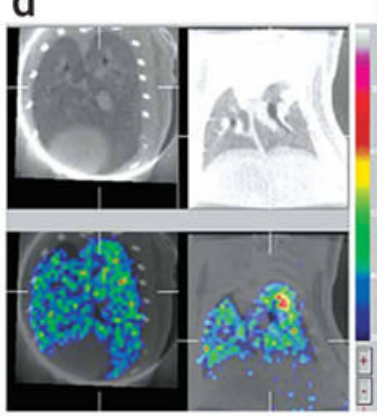

b

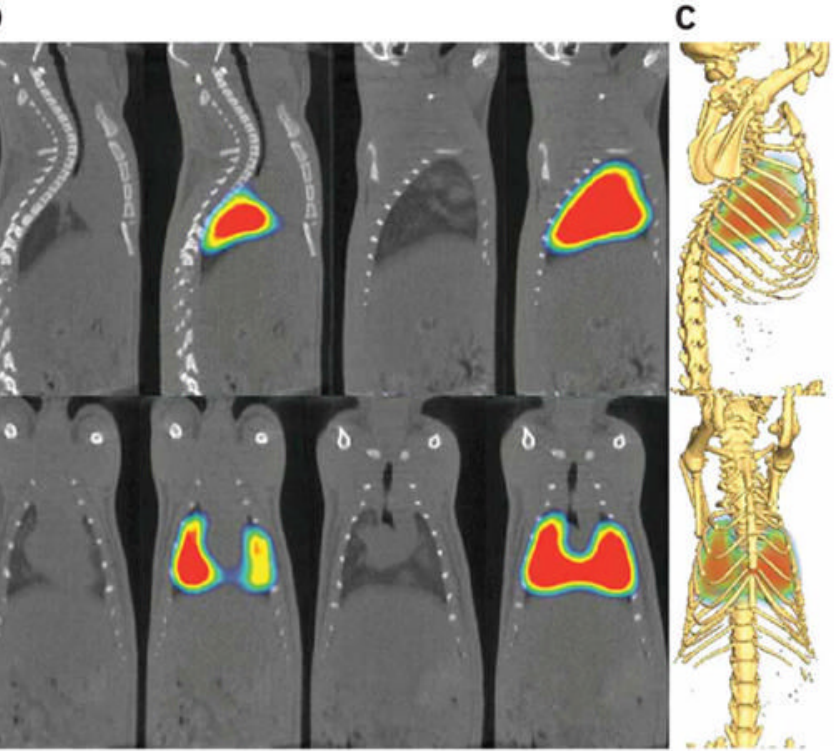

e

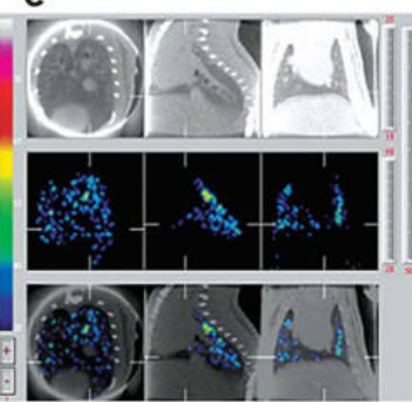

f

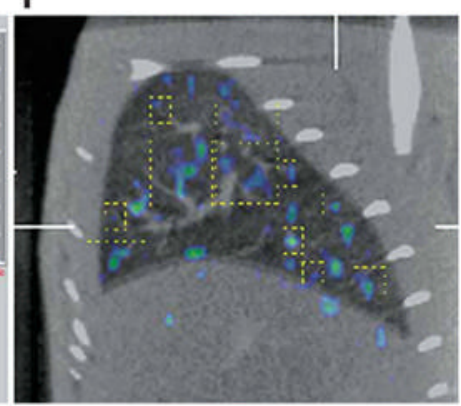

Figure 7.

SPECT/CT imaging of mAPP targeting to lung and its vasculature. (a) Axial slices along the thoracic vertebrae showing mAPP localization within the rat lung. (b) Top-sagittal slices and bottom-coronal slices. (c) Fusion of volumetric SPECT texture with CT isosurface showing mAPP localization within the rat lung. (d,e) Pinhole SPECT images of lung accumulation of ${ }^{99 \mathrm{~m}}$ Tc-mAPP 30 min post-injection (e, middle panels), X-ray CT scans of the same region in rats (d,e, top panels), and overlay of the two images (d,e, bottom panels). (f) High magnification SPECT/X-ray CT images showing accumulation of ${ }^{99} \mathrm{~m}$ Tc-mAPP in the smaller vessels (dashed yellow line) of the lung. CT scans and gamma scintigraphy fused CT-SPECT images of rats injected i.v. with mAPP radiolabeled with ${ }^{125} \mathrm{I}(\mathbf{a}-\mathbf{c})$ or ${ }^{99 \mathrm{~m}} \mathrm{Tc}(\mathbf{d}-\mathbf{f})$. 